Virág Véber

\title{
The Power of Perspective. Discrimination Against Men
}

\section{Introduction}

Human societies are extremely diverse. People can be categorized on the basis of many differences: in addition to ethnic, racial, gender and religious differences, there is also strong diversity in social and economic status and political affiliation. These categories inadvertently lead to stereotypes and biases: we want to systematize this diversity in some way, so we classify people by type; we assign some characteristics to classes, and based on these, we set expectations for the members of a group according to how we think of them.

Everyone has ideas about the nature of men and women and what they are like. Most people, often in spite of their conscious beliefs, values, and attitudes have prejudices, and these influence their behaviour. For example, various experiments where employers or average participants had to evaluate job applicants on the basis of biographies and other written material, provide convincing evidence of unequal treatment of women. ${ }^{1}$ In these experiments, one group of participants received a biography with a female name, the other group with a male name, and all participants received multiple profiles, including a woman and a man, who were completely identical in qualifications based on pre-testing. These studies find that female candidates receive, on average, worse judgments, lower pay bids, fewer chances of being called for an interview or being hired.

The purpose of this essay is to show that it is not just women who are discriminated but men also suffer the consequences of inequality in gender binary. I build my case on one of the most important keywords in recent research, the notion of "stereotype threat". By using this concept and leaning on Stacey Goguen's thoughts, I show how we could widen our perspective in this area. ${ }^{2}$ Many times - as I will aim to show - we are stuck in prejudices against women, which will make our picture of the whole issue of gender incomplete. As John Archer and Barbara Lloyd write in Sex and Gender: "Commonsense beliefs about men and women are not arbitrary. They are associated with coherent ways of understanding the world in which we live, which for many

1 Koch et al. 2015.

2 Goguen 2016. 
centuries have been presented to each succeeding generation in the form of religious truths." ${ }^{3}$ We maintain social hierarchy, such as sexism, openly threaten the status quo between the dominant group and outside groups by rejecting views that justify the status of the dominant group. Both hostile and benevolent sexism prescribe traditional roles for the sexes. The gender problem should be seen as a whole, a change of perspective should be important and an integrated solution should be found. Feminism will not succeed if we fight only and exclusively for women's equality and the elimination of prejudice against them.

\section{Stereotype threat, social identity threat and epistemic costs}

Brian Nosek et al.'s international study of stereotypes found that people more easily associate science with men than women, and this trend predicted the performance gap between boys and girls in STEM and art subjects at school. ${ }^{4}$ On the one hand, we can explain this relationship by reference to direct discrimination, and on the other hand, prejudices can be so profound that they indirectly act as a self-fulfilling prophecy. This is related to Claude Steele's psychological experiment in which he examines the socalled stereotype threat. ${ }^{5}$ In the study, members of a stereotyped group had to perform a task that, according to the stereotype, the members of the group underperformed; for example, blonde women had to solve a logical puzzle. The result of the experiment was that those who received some comment about their stereotype against their sex performed worse, and those who were not prejudiced against during the experiment solved the task better. Based on these, if we imagine how children can be influenced at school age, we see that teachers' or parents' beliefs about girls' and boys' abilities play an important role in shaping student performance. So, stereotype threat is "the resulting sense that one can [...] be judged or treated in terms of the stereotype". 6 The best known effects of stereotype threat is the underperformance effect (an unintentional decrease in performance), psychological disengagement (a reduction in motivation to participate or succeed in a certain domain) and domain avoidance (individuals physically avoid or socially distance themselves from a domain) ${ }^{7}$ - the last two of which are considered as indirect effects. Moreover, stereotype threat's effects on stress, motivation,

3 Archer - Lloyd 2002, 3.

4 Nosek et al. 2009.

5 Steele-Aronson 1995.

6 Steele et al. 2002, 389.

7 Goguen 2016, 
and aspiration are not new information: there is a "two-pronged consequence of stereotype threat - undermining both performance and aspirations". ${ }^{8}$

In his paper, Ron Mallon argues that behaviours affected by stereotype threat should be interpreted as deliberate, strategic responses to social circumstances. ${ }^{9}$ His view stands in opposition to more typical analyses that model such responses as resulting from hypervigilance triggered by automatic, Type 1, "subpersonal" processes. Although he does not seek to displace subpersonal processes in the explanation of stereotype threat completely, his broad aim is to make space for a non-alienating explanation of stereotype threat, i.e. an explanation that does not treat stereotype threat as something that completely bypasses our capacities as believing, desiring, and intending agents. On Mallon's view, we can make sense of stereotype threat in terms of our intuitive grasp of what rational actors do in socially threatening situations.

Stacey Goguen claims that stereotype threat has significant consequences for epistemic aspects of our lives - consequences which have been underemphasized by both psychologists and philosophers. ${ }^{10}$ Goguen focuses on tracing out one such consequence: self-doubt. She argues that self-doubt can undermine epistemic self-trust, often by challenging a person's faith in their own rationality. The result is that stereotype threat can lead to a particular kind of epistemic injustice in that it can cause a person to question their own status as a rational and reliable knower, due to unfair and stigmatizing stereotypes about them. This effect is important, because it helps to flesh out two important claims - one made within stereotype threat research, and one within epistemic injustice scholarship. The first claim is that stereotype threat has a much wider range of effects than those on which researchers and scholars usually focus. The second claim is that epistemic injustice not only damages one's ability to produce and access knowledge, but also damages and distorts one's sense of self. According to Goguen, stereotype threat has a much broader and deeper scope than researchers generally think; it damages and distorts an individual's self-confidence; it casts doubt on people's belief in their own rationality.

The difference between the two positions is that while Mallon ignores the agent who is able to believe and desire, Goguen puts the individual at the centre: it is precisely the individual's own status that can be questioned as a rational and reliable cognitive agent because of unfair and stigmatizing stereotypes. In my view, Goguen's argument is more interesting not just because it describes the problem of male-female stereotypes more adequately, but it also highlights that stereotype threat has more far-reaching implications than a number of unexplored epistemic effects. She argues that we need to

8 Davies et al. 2005, 278.

9 Mallon 2016.

10 Goguen 2016. 
apply the stereotype threat more broadly and show how such an account helps us better understand the consequences of a particular epistemic effect: the lack of self-confidence in specific scenarios. As she wrote: "Certain types of self-doubt can constitute epistemic injustice, and this sort of self-doubt can be exacerbated by stereotypes of irrationality."11 As a result, the self-doubt that comes from a stereotype threat can weaken our faith in ourselves as whole, rational and reliable humans. Stereotype threat may not only affect our ability, it also has a great impact on how we feel as a person. In addition, the use of a broader account allows us to better examine the epistemological implications of stereotype threat and its full extent into our lives - regardless of gender.

According to Goguen, the underperformance effect, which was mentioned above, is not a good theoretical basis to see a fuller account of stereotype threat. As she wrote: "An expanded framework that equally encompasses the effects beyond performance provides better conceptual connections to related psychological phenomena. Furthermore, an expanded account opens up avenues of both psychological and philosophical research that a focus on underperformance would likely obscure." ${ }^{12}$ Goguen says that disengagement and domain avoidance should be considered direct effects of stereotype threat as much as underperformance does - "in fact, work on the concept of psychological threat more generally suggests that all of stereotype threat's effects can be tied to various strategies individuals use to cope with such threats". ${ }^{13}$ She proposes Steele, Spencer and Aronson's broader framework to be called "social identity threat". ${ }^{14}$ With this theory, we can define the condition that occurs when people are aware that they are judged negatively or devalued because of belonging to a particular social group. After that, we can deem underperformance, disengagement and domain avoidance as manifestations of different coping strategies that people undertake in response to potentially being devalued - because all three of them are part of individuals' reactions to threats of devaluation that are triggered by the presence and possible salience of a negative stereotype. ${ }^{15}$

Goguen would add one more field to this account: fleshing out a stereotype threat's epistemological implications. A stereotype threat has many more "epistemic costs" than we might think: by epistemic cost, she means "any negative effect on a facet of our lives that deals with how we gain, retain, and disseminate knowledge" ${ }^{16}$ For instance, the cognitive mechanisms that lead to underperformance could do so in part by temporarily causing people to lose confidence in their knowledge, such as whether $6 \times 6$ is 36 , or

11 Goguen 2016, 216.

12 Goguen 2016, 219.

13 Goguen 2016, 220.

14 Steele et al. 2002.

15 Goguen 2016, 221.

16 Goguen 2016, 222. 
which is my right hand - if we could sincerely doubt something such as whether we have two hands, that doubt would have serious ramifications for our epistemic life. If we are starting to doubt of a fact like that, we probably will (and probably should) also start doubting other, more fundamental propositions about ourselves, such as whether we are capable of reliable perception (such as gaslighting as an extreme version). Such things can penetrate into deeper, more important aspects of ourselves ("cognitive spillover"). ${ }^{17}$

Goguen nicely demonstrated how useful the broader framework is, because it helps to see the connections between these phenomena. Stereotype threat is not just about underperformance, it affects our whole lives.

\section{Ambivalent sexism}

We need to realize that stereotype threat and its epistemic costs affect both sexes. As Noëlle McAfee writes: "sexism is not only harmful to women, but is harmful to all of us". ${ }^{18}$ Sexism can be used to refer to anything that creates, constitutes, promotes, sustains, or exploits an unjustifiable distinction between the sexes. ${ }^{19}$ It is one of the epistemic costs, because it destabilizes women and men in their belief that they can do whatever they want, regardless of gender. Men and women have had different gender roles for centuries: man was largely the breadwinner, an employee with self-assertion duties, women ran the household. These gender roles and responsibilities have created and reinforced gender norms and perceived traits, and women are not only viewed negatively, just as men are not only viewed positively. Ambivalent sexism offers a multidimensional reconceptualization of the traditional view of sexism.

The ambivalent sexism theory has largely been developed by social psychologists Peter Glick and Susan Fiske. According to them, we can distinguish hostile sexism and benevolent sexism. ${ }^{20}$ Hostile sexism reflects overtly negative evaluations and stereotypes about a gender (e.g. the ideas that women are incompetent and inferior to men, or that men are aggressive and not caring to women). Benevolent sexism represents evaluations of gender that may appear subjectively positive (subjective to the person who is evaluating), but are actually damaging to people and gender equality more broadly (e.g., the ideas that women need to be protected by men or it is better to leave household money to women than to leaving it to men).

17 Goguen 2016, 224.

18 McAfee 2018.

19 Frye 1983, 18.

20 Glick - Fiske 1997. 
The problem with hostile sexism is clear: it is hurtful to say that women are incompetent and inferior to men, or that men are aggressive and not caring to women. Seemingly, there is nothing wrong with benevolent sexism: it describes both sexes specifically as superior in certain things. But if we take a closer look, we say that women are biologically worse at something, then we say that men are biologically better at the same time, so we proclaim the biological inferiority of women. Or vice versa: we say that women are biologically better at something, then we say that men are biologically worse at the same time at that thing, so we proclaim the biological inferiority of men. It is a mistake to believe that feminists proclaim the inferiority of men. Feminism is a civil rights movement for gender equality, discrimination against women. The fact that opponents of feminism view the pursuit of equality as an attempt to oppress men merely disguises their own ideology based on the inferiority of women, and they expect others to have a hierarchical worldview in terms of gender. This misunderstanding may even come from the general perception of feminists, which is not always positive: they are considered to be man-haters, and this is also helped by the fact that for the most part, psychologists have studied hostile forms of sexism, which is also full of negative examples of men.

Furthermore, a serious problem with benevolent sexism is that whoever does not meet the needs to the idealized image (not a caring, pretty woman, and not a strong, independent man) is received with aversion and malice. ${ }^{21}$ And benevolent sexism maintains the status quo: even if women feel that they are sacrificing their perceived rationality and competence, they receive benevolent treatment in return. Thus, many will not feel the need to criticize or go against this system. Of course, this will also be true of men. And here we come to the point that it is not only women who are affected, but men as well. After that, all the perceived traits that we have listed so far in women can be listed roughly in reverse in men. We see men as rational, intelligent, dominant, competent, assertive, yet aggressive, violent, and arrogant. ${ }^{22}$

\section{The perspective of men}

The stereotype threat is as much an issue for men as it is for women. In Koenig and Eagly's experiment, they measured social sensitivity: men had to confront with their gender stereotypes. ${ }^{23}$ Furthermore, men are also less likely to be seen in gender-atypical

21 Heilman - Okimoto 2007.

22 Eagly - Mladinic 1994.

23 Koenig - Eagly 2005. 
areas in the labour market. ${ }^{24}$ It is not just about stereotype threat - it is about destroying men's self-confidence, and questioning their suitability for other atypical tasks. To solve this, we would need to handle this issue as a social identity threat.

The epistemic costs are not questionable. Why do men choose typical men jobs? On the one hand, feminine work is not well-paid, but the social expectation is that men have to be rich and successful. On the other hand, because as a man, being a kindergarten teacher, a secretary, a nurse or a manicurist is not masculine. Theories and research describing "fragile masculinity" suggest that masculinity is easier to lose than femininity. ${ }^{25}$ Masculinity is treated as a status that must be demonstrated, proven, and won over and over again. Thus, men are particularly sensitive to signals that threaten their manhood. This has been demonstrated in a related experiment: when male participants had to braid hair, more of them chose boxing rather than doing puzzles afterwards compared to those who only had to braid a rope. ${ }^{26}$ Or, to bring another example: doing or not doing housework regularly can be an "indication" of internalized gender expectations - especially in the case of poorer men, due to the fact that they had to compensate for their limited financial situation, they tried to emphasize their masculinity by militant resistance to domestic work. ${ }^{27}$ In these situations, therefore, husbands who were economically dependent on their wives thought they would strengthen their role as social men by not doing housework. This process can be described by the concept of "doing gender", ${ }^{28}$ which is defined as involving the everyday performance of "a complex of socially guided perceptual, interactional, and micropolitical activities that cast particular pursuits as expressions of masculine and feminine 'natures". ${ }^{29}$ In doing so, women strengthen their femininity by caring for children and other family members (which includes doing housework), while men can show their masculinity by exercising their role as a breadwinner - and not performing tasks such as those expected of women, like doing housework. ${ }^{30}$ Based on similar experiments, having questioned their masculinity, men behave more dominantly. ${ }^{31}$

The maintenance of masculinity is otherwise likely to be stressful: adherence to male norms is positively correlated with depression and psychological stress. ${ }^{32}$ Gender norms prescribe men's everyday behaviour patterns: emotions and vulnerability are taboo, and men are not unreasonably afraid of judging others, as if men behave in a

24 Davison - Burke 2000.

25 Vandello - Bosson 2013.

26 Bosson et al. 2009.

27 Brines 1994.

28 West-Zimmermann 1987.

29 West - Zimmermann 1987, 126.

30 Yavorsky et al. 2015.

31 Dahl et al. 2015.

32 Magovcevic - Addis 2008. 
"feminine" way (e.g., emotionally) or perform "feminine" tasks, they are laughed at, degraded, and despised. ${ }^{33}$ Even today, we can encounter that point of view that men who are "too sensitive", "even crying", are "not so masculine". I am sure most parents still tell their young sons not to cry because only girls cry (as if this were a sign of weakness).

Although the dual-earner family model is becoming more widespread, in spite of changes in family structures, the traditional gender-segregated division of labour within the family and the resulting inequalities in domestic work and parental responsibilities have persisted..$^{34}$ Raising children is still seen by many as almost exclusively a maternal duty, as women are "by nature" thought to be better suited to care for others than men - even in societies where the vast majority of women do paid work. ${ }^{35}$

According to traditional gender roles, it is also expected that they are the (main) breadwinners, so sometimes the responsibility of supporting the whole family is on their shoulders. This is largely what their main role in the family is about. The place of woman is "at home" because her primary and most important role is to give birth to and raise children. ${ }^{36}$ She is the mother, the most important person in the child's life. Who is not the main parent, who is secondary? The father. Men are essentially excluded from relationships with very young children. ${ }^{37}$ There is less talk about this topic than discrimination in the workplace, although this is a general, cross-cultural example, as well as traditions of child placement at divorce. The practice of recent decades has been for the child to be placed in the mother's custody, regardless of who cares more about them: mothers' right to raise children is generally stronger than the interests of fathers. ${ }^{38}$ This convention also exists as the de facto solution in Hungary. ${ }^{39}$ Men have to even fight against their gender role if they want to look after their own children. They are often overlooked or neglected in this way, because they are not expected to be caring and nurturing.

Women have a pretty hard time finding their way into traditionally male-dominated (e.g. tech) occupations and leadership positions, but at the same time, men have a hard time if they want to work in, for example, childcare. So, women are discriminated in work, and men are discriminated in family life. In most capitalist economies, because of their labour market advantages, men have more money, resources, and power, they are largely the decision-makers who influence the events of the world. Meanwhile, one

33 Burris et al. 2016.

34 Milkie et al. 2010.

35 Silverstein - Auberbach 1999.

36 Okimoto - Heilman 2012.

37 Connell 2012, 319.

38 Connell 2012, 319.

39 Grád et al. 2008. 
of the most important values in a person's life is family, relationships, and love, where women's roles and perceived qualities take precedence.

\section{Conclusion}

What I have discussed here is but one of many lines of inquiry we can take up from an expanded account of stereotype threat. In summary, stereotype threat's effects on performance are important, but this is not the whole picture. Stereotype threat has many other effects, such as anxiety, disengagement, domain avoidance, and self-doubt. We also need to talk about the two types of sexism - both of them are harmful, and they can be classified as epistemic costs.

If it is not easier for men either, why do we not hear them fight for their rights? On the one hand, because this would be contrary to male norms: they would look weak as a result (vicious circle). On the other hand, the mentioning of prejudice against men is described by many as minimizing the disadvantages of women. Though this is not a competition. This is the reason why it is important to see the gender problem as a complex issue and thus find an integrated solution. Since as long as people look down on men who want to stay at home with their children, the woman stays at home..$^{40}$ And since as long as a man with a female superior feels losing his masculinity, he will not support a female superior. ${ }^{41}$

While the husband is expected to be more successful, the wife even intentionally limits her own successes, so that they both meet social expectations. ${ }^{42}$ As long as a man needs to be strong, high-status, dominant, and sexually successful, he will maintain the gender hierarchy, because it is precisely the expectation that he has to own money and power. We can only eliminate unfair expectations and treatment of women if we also eliminate unfair expectations and treatment of men.

This suggests that we should consider shifting some of our perspectives regarding underrepresentation. For instance, instead of accepting as a given that fields like engineering simply do not seem desirable career choices for many women, we can investigate whether stereotype threat plays a role in the degree to which engineering comes off desirable or as stressful and potentially threatening to women's self-worth. However, it should be no surprise that individuals tend to avoid domains where they experience increased levels of stress, lower motivation, and greater potential for feeling worthless.

40 Rudman - Mescher 2013.

41 Berdahl et al. 2018.

42 Bertrand et al. 2015. 
The impact of the stereotype threat on performance is important, but it is also important that it does not give us not the whole picture. I stressed above that these effects apply not only to women but also to men. It is worth talking about stereotype threat and social identity threat in terms of both genders, because women are not the only ones who are discriminated.

\section{Bibliography}

Archer, John - Barbara Lloyd. 2002. Sex and gender. Cambridge: Cambridge University Press.

Bem, Sandra Lipsitz. 2008. "A biológiai esszencializmus." in Rasszizmus a tudományban, edited by Kende Anna - Vajda Róza, 147-198. Budapest: Napvilág Kiadó.

Berdahl, Jennifer L. - Marianne Cooper - Peter Glick - Robert W. Livingston - Joan C. Williams. 2018. "Work as a masculinity contest." Journal of Social Issues 74/3: 422-448. DOI: 10.1111 josi.12289.

Bertrand, Marianne - Emir Kamenica - Jessica Pan. 2015. "Gender identity and relative income within households." The Quarterly Journal of Economics 130/2: 571-614. DOI: 10.1093/qje/ qjv001.

Bosson, Jennifer K. - Joseph A. Vandello - Rochelle M. Burnaford - Jonathan R. Weaver - S. Arzu Wasti. 2009. "Precarious manhood and displays of physical aggression." Personality and Social Psychology Bulletin 35/5: 623-634. DOI: 10.1177/0146167208331161.

Brines, Julie. 1994. "Economic dependency, gender, and the division of labor at home." American Journal of Sociology 100/3: 652-688. DOI: 10.2307/2782401.

Burris, Christopher T. - Kristina M. Schrage - John K. Rempel. 2016. "No country for girly men: High instrumentality men express empathic concern when caring is 'manly." Motivation and Emotion 40/2: 278-289. DOI: 10.1007/s11031-015-9525-7.

Dahl, Julia - Theresa Vescio - Kevin Weaver. 2015. "How threats to masculinity sequentially cause public discomfort, anger, and ideological dominance over women." Social Psychology 46/4: 242-254. DOI: 10.1027/1864-9335/a000248.

Davies, Paul - Steven Spencer - Claude Steele. 2005. "Clearing the air: Identity safety moderates the effects of stereotype threat on women's leadership aspirations." Journal of Personality and Social Psychology 88/2: 276-287. DOI: 10.1037/0022-3514.88.2.276.

Davison, Heather K. - Michael J. Burke. 2000. "Sex discrimination in simulated employment contexts: A meta-analytic investigation." Journal of Vocational Behavior 56/2: 225-248. DOI: 10.1006/jvbe.1999.1711.

Connell, Raewyn W. 2012. Utószó: A maszkulinitás politikája jelenleg. Férfiak. Eltünő szerepek, 315-341. Ford.: Dudik Annamária Éva. Budapest: Noran Libro.

Eagly, Alice H. - Antonio Mladinic. 1994. "Are people prejudiced against women? Some answers from research on attitudes, gender stereotypes, and judgments of competence." European Review of Social Psychology 5/1: 1-35. 
Frye, Marilyn. 1983. The Politics of Reality. Trumansburg, NY: The Crossing Press.

Glick, Peter - Susan T. Fiske. 1997. "Hostile and Benevolent Sexism." Psychology of Women Quarterly 21: 119-135. DOI: 10.1111/j.1471-6402.1997.tb00104.x.

Goguen, Stacey. 2016. “Stereotype Threat, Epistemic Injustice, and Rationality.” In Implicit Bias and Philosophy, edited by Michael Brownstein - Jennifer Saul, 216-237. Oxford: Oxford University Press.

Grád, András - Gyöngyvér Jánoskúti - András Kőrös. 2008. "Mítosz és valóság: A gyermekelhelyezési perek tapasztalatai a statisztikai adatok fényében - 2. rész.” Családi Jog 6/4: 8-15.

Heilman, Madeline E. - Tyler G. Okimoto. 2007. "Why are women penalized for success at male tasks? The implied communality deficit." Journal of Applied Psychology 92/1: 81-92. DOI: $10.1037 / 0021-9010.92 .1 .81$.

Koch, Amanda J. - Susan D. D’Mello - Paul R. Sackett. 2015. "A meta-analysis of gender stereotypes and bias in experimental simulations of employment decision making." Journal of Applied Psychology 100/1: 128-161. DOI: 10.1037/a0036734.

Koenig, Anne M. - Alice H. Eagly. 2005. "Stereotype threat in men on a test of social sensitivity." Sex Roles: A Journal of Research 52/7-8: 489-496. DOI: 10.1007/s11199-005-3714-x.

Magovcevic, Mariola - Michael E. Addis. 2008. “The Masculine Depression Scale: development and psychometric evaluation.” Psychology of Men \& Masculinity 9/3: 117-132. DOI: 10.1037/1524-9220.9.3.117.

Mallon, Ron. 2016. "Stereotype Threat and Persons." In Implicit Bias and Philosophy, edited by Michael Brownstein - Jennifer Saul, 130-156. Oxford: Oxford University Press.

McAfee, Noëlle. 2018. "Feminist Philosophy." In The Stanford Encyclopedia of Philosophy (Fall 2018 Edition), edited by Edward N. Zalta. [https://plato.stanford.edu/archives/fall2018/ entries/feminist-philosophy] (26.01.2021.)

Milkie, Melissa A. - Sarah M. Kendig - Kei M. Nomaguchi - Kathleen E. Denny. 2010. "Time with children, children's well-being, and work-family balance among employed parents." Journal of Marriage and Family 72/5: 1329-1343. DOI: 10.1111/j.1741-3737.2010.00768.x.

Nosek, Brian A. - Frederick L. Smyth - N. Sriram - Nicole M. Lindner - Thierry Devos Alfonso Ayala - Yoav Bar-Anan - Robin Bergh - Huajian Cai - Karen Gonsalkorale - Selin Kesebir - Norbert Maliszewski - Félix Neto - Eero Olli - Jaihyun Park - Konrad Schnabel - Kimihiro Shiomura - Bogdan T. Tulbure - Reinout W. Wiers - Mónika Somogyi - Nazar Akrami - Bo Ekehammar - Michelangelo Vianello - Mahzarin R. Banaji - Anthony G. Greenwald. 2009. "National differences in gender-science stereotypes predict national sex differences in science and math achievement." PNAS Proceedings of the National Academy of Sciences of the United States of America 106/26: 10593-10597. DOI: 10.1073/ pnas.0809921106.

Okimoto, Tyler G. - Madeline E. Heilman. 2012. "The 'bad parent' assumption: How gender stereotypes affect reactions to working mothers." Journal of Social Issues, 68/4: 704-724. DOI: $10.1111 /$ j.1540-4560.2012.01772.x.

Rudman, Laurie A. - Kris Mescher. 2013. "Penalizing men who request a family leave: Is flexibility stigma a femininity stigma?” Journal of Social Issues 69/2: 322-340. DOI: 10.1111/ josi.12017. 
Silverstein, Louise B. - Carl F. Auerbach. 1999. "Deconstructing the essential father." American Psychologist 54/6: 397-407. DOI: 10.1037/0003-066X.54.6.397.

Steele, Claude - Joshua Aronson. 1995. „Stereotype Threat and the Intellectual Test Performance of African Americans." Journal of Personality and Social Psychology 69/5: 797-811. DOI: 10.1037/0022-3514.69.5.797.

Steele, Claude M. - Steven J. Spencer - Joshua Aronson. 2002. "Contending with group image: The psychology of stereotype and social identity threat." Advances in Experimental Social Psychology 34: 379-440. DOI: 10.1016/S0065-2601(02)80009-0.

Vandello, Joseph A. - Jennifer K. Bosson. 2013. "Hard won and easily lost: A review and synthesis of theory and research on precarious manhood." Psychology of Men \& Masculinity 14/2: 101-113. DOI: $10.1037 / \mathrm{a} 0029826$.

West, Candace - Don Zimmerman. 1987. “Doing Gender.” Gender and Society 1/2: 125-151.

Yavorsky, Jill E. - Claire M. Kamp Dush - Sarah J. Schoppe-Sullivan. 2015. “The Production of Inequality: The Gender Division of Labor Across the Transition to Parenthood." Journal of Marriage and Family 77: 662-679. DOI: 10.1111/jomf.12189. 